\title{
Study of Seroprevalence and Seroconversion to A Novel Bacterial Pathogen in Thoroughbred Horses
}

\author{
Rajasekariah G-Halli1*, Hudson $\mathrm{BJ}^{2}$, Chicken $\mathrm{C}^{3}$, Blishen $\mathrm{A}^{3}$, \\ Perriam $\mathrm{W}^{4}$ and Corones $\mathrm{G}^{5}$ \\ ${ }^{1}$ Biofirm Pty Ltd 19 Burraneer Avenue St Ives NSW 2075, Australia \\ 2Department of Microbiology \& Infectious Diseases, Royal North Shore Hospital, \\ St Leonards New South Wales, Australia \\ ${ }^{3}$ Scone Equine Hospital, 106 Liverpool Street, Scone NSW Australia \\ ${ }^{4}$ Gundy Veterinary Services, P.O. Box 445, Scone NSW Australia \\ ${ }^{5}$ Corones O'Hehir Veterinary Services, 260 Russell Street, Bathurst NSW Australia
}

\section{Research Article \\ Volume 3 Issue 1}

Received Date: January 02, 2019

Published Date: January 28, 2019

DOI: $10.23880 / v i j-16000203$

*Corresponding author: Dr. G-Halli Rajasekariah, Biofirm Pty Ltd, 19 Burraneer Avenue St Ives NSW 2075, Australia, Email grajasekariah@gmail.com

\begin{abstract}
Infection caused by Kingella kingae is an emerging infection in young children manifest primarily as bacteremia and osteoarticular infection (OAI). Asymptomatic infection is common, based on throat swab and serology studies in pediatric populations. A novel bacterial species was identified by MALDI-TOF as Kingella kingae, in synovial and bone tissues surgically debrided from thoroughbred horses, aged between 3 and 15 months, with OAI. Molecular studies (16s rRNA) indicated the organism was not Kingella kingae, but is likely a novel species. Subsequently we investigated serological responses to Kingella kingae and the novel equine species. We tested serum samples from three separate herds by indirect immunofluorescence antibody test (LED-IFAT) using a pathogenic human isolate of Kingella kingae and the novel equine species as substrates. Equines in Farm A showed no evidence of antibodies to Kingella and therefore served as the control herd. Seropositivity was detected in equines in Farm B (5/10 tested) and Farm C (1/9 tested). In Farm B, 1/5 seropositives demonstrated seroconversion on paired sera. Based on this preliminary study, it is possible to detect by LED-IFAT antibodies to a previously unidentified equine pathogen, and this assay may be of value in screening herds to determine seroprevalence and seroconversion rates for this novel pathogen.
\end{abstract}

Keywords: Kingella; Thoroughbred Horses; Immunological Testing; Seropositives; Sero-Conversion; LED-IFAT Test 


\section{Virology \& Immunology Journal}

\section{Introduction}

Kingella kingae is a gram-negative aerobic coccobacillus, first isolated in 1960 from children, and originally classified as Moraxella but subsequently transferred to the genus Kingella [1]. It was not until 1990 that culture and other techniques indicated that it was a significant cause of infection in young children [2] We have recently detected a novel bacterial species, identified by MALDI-TOF as Kingella kingae, in synovial and bone tissues surgically debrided from thoroughbred horses, aged between 3 and 15 months, with osteoarticular infection (OAI). Molecular studies (16s rRNA) indicated the organism was not Kingella kingae, but is likely a related but novel species (see GenBank Accession number KR494280). There are no data on Kingella infection in horses and there is only one other animal isolate of Kingella (Kingella potus) - isolated from the wound of a zookeeper bitten by a kinkajou (Potus flavus) [3]. The latest publication of Equine Medicine [4] does not mention any potential infection with Kingella species, nor is there any literature found on internet search, using the words "Kingella", "horses", "equine".

$K$. kingae infection in humans is an emerging infection with clinical manifestations including OAI such as osteomyelitis, septic arthritis, vertebral osteomyelitis. $K$. kingae is part of the normal flora of the upper respiratory tract and oral cavity in young children and is likely transmitted via respiratory droplets or direct contact [5]. Yagupsky reported high incidence of $K$. kingae among children, and high rates of transmission, in day care centers (DCC) in the United States, France, Israel and other countries [5]. $K$. kingae is reported as the commonest cause of OAI in young children, between 6 months and 5 years of age in France and Italy, and likely most developed countries [5-7]. When it causes disease, clinical presentation is often subtle and preceded by a recent history of stomatitis or upper respiratory infection [5]. As our recently discovered isolate from a bone specimen taken from a young equine with OAI appears to be related to $K$. kingae (based on 16s rRNA sequence deposited in GenBank - Accession number KR494280), there may be similarities between human and equine infection.

A sporadic case report is analogous to the situation in humans that led to the discovery of widespread infection and invasive disease due to $K$. kingae in humans (children) [2] [5]. We have investigated the possibility of developing a reliable serology assay to detect seroconversion as this should assist in epidemiological

investigation, prevention and control of the infection. A serum-based IFAT (LED-immunofluorescent antibody test) was investigated. LED-IFAT has often been used as a gold standard test for the diagnosis of several infections $[8,9,10,11]$ as such test could be used as a first step in developing an automated assay that facilitates testing large numbers of specimens.

\section{Materials and Methods}

\section{Bacteria}

A strain of Kingella kingae, isolated from synovial fluid in a young child with septic arthritis, was grown in a lawn culture on chocolate agar under microaerophilic conditions. Similarly, an isolate of the novel equine species (hereinafter referred to as $K$. equi), derived from culture of bone from a 7-month old thoroughbred filly suffering from OAI, was also propagated on chocolate agar under microaerophilic conditions. Whilst $K$. kingae typically forms Gram negative rods that are straight, have round or square ends and have dimensions of 0.6-1.0 by 1.0-3.0 microns, and may form pairs and short chains, $\mathrm{K}$. equi was more likely to form cocco-bacilli of variable size, and often formed long chains (Gram stain Fig 1 A and B). Colony suspensions of both $K$. kingae and $K$. equi were prepared and used for testing.

\section{(A)}

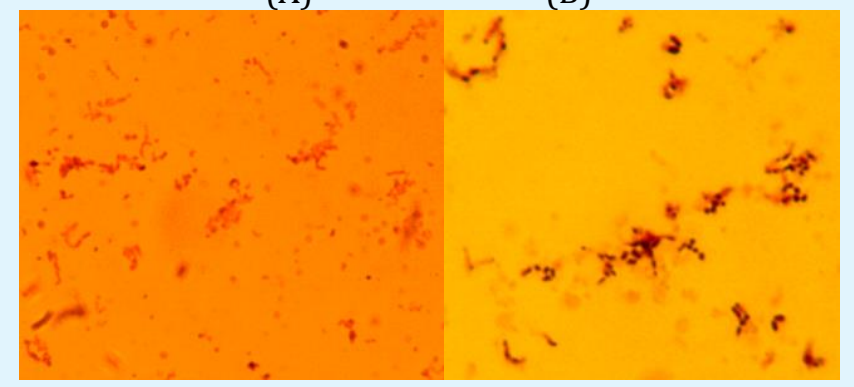

Figure 1: (A) Human isolate, Kingella kingae and (B) Equine isolate $K$. equi.

\section{Processing Bacterial Suspension and Preparation of Slides for IFAT}

The colony suspensions were harvested into a mammalian conditioned buffer and purged through a $26 \mathrm{~g}$ needle attached to a syringe. Upon purging a single cell bacterial suspension free of clumps was obtained which was washed three times in mammalian conditioned buffer. Washed preparations were again purged through a $26 \mathrm{~g}$ needle for maintaining a single bacterial cell suspension. Appropriate dilutions were made in such a 


\section{Virology \& Immunology Journal}

way that by spotting a $2 \mu \mathrm{l}$ spot onto a one- or multi-well ( $8 \mathrm{~mm}$ diameter) slides should leave an ultrathin layer of Kingella bacteria on the solid phase. Once achieved, then the required numbers of slides were spotted, air dried and fixed in acetone, and stored under dry conditions at $4^{\mathrm{o}} \mathrm{C}$ until used. Subsequently, serum samples were tested in parallel with $K$. kingae and $K$. equi spotted $(8 \mathrm{~mm})$ slides. These multi-well slides carrying the spotted bacteria were used as substratum for detection of antibodies in thoroughbred horse serum samples.

\section{Optimisation of Serum Dilution for Determination of LED-IFAT as Exposure Assay}

Serum samples were available from stored sera that had been collected retrospectively from horses resident on three different farms (Farms A, B and C). Some of these serum samples had previously been collected from yearlings (on the farms) that had been diagnosed as having OAI for which either the novel organism (K. equi) or no cause had been found. Others had been collected from otherwise healthy yearlings in the same cohort as the affected yearlings. No OAI had been diagnosed on Farm A, so serum samples from residents of Farm A were used as controls.

Serum samples were separated from blood clots, centrifuged, and collected into fresh tubes and labeled carefully with specific date of collection, and stored at $-20^{\circ} \mathrm{C}$. The frozen stock of serum was taken out, thawed and a stock dilution of $1 / 100$ was made by using frozen mammalian conditioned buffer as the diluent. A series of dilutions were made to test the serum in LED-IFAT.

\section{Development of Kingella Antibody Detection Assay}

A panel of sera from different farms was tested in order to develop the LED-IFAT and validating the assay. One horse (B-20), was the index case, being the first horse suffering from $\mathrm{OAI}$ and from which the novel equine species had been isolated. This individual's serum tested positive for antibody to both $K$. kingae and $K$. equi. This serum was used as the reference positive (Figure 2,3) control standard. The test had to be free of non-specific fluorescence. The Kingella bacteria were immobilized on solid phase $(8 \mathrm{~mm}$ diameter single well and $6 \mathrm{~mm}$ diameter multi-well glass slide). Serum was titrated (added $30 \mu \mathrm{l}$ per well) in series and reacted against Kingella isolates and incubated at $37^{\circ} \mathrm{C}$ for 30 minutes. The slide was washed in $0.85 \%$ Normal saline (isotonic saline), and then air-dried. Then $30 \mu \mathrm{l}$ of goat anti-equine antibody labeled with FITC (VMRD) was used as the secondary antibody and further incubated for 30 minutes at $37^{\circ} \mathrm{C}$. After incubation, slides were rinsed in isotonic saline and air-dried and mounted with mounting fluid and visualized under LED-IF microscope. Those slides showing positive immunofluorescence were identified as "Positive" and those not showing any fluorescence were marked as "Negative". Sera were tested in doubling dilutions from $1 / 200$ up to and including $1 / 3200$, and then incubated for 30 minutes at $37^{\circ} \mathrm{C}$. A dilution of $1 / 400$ serum was determined to be free from any non-specific binding of second antibody and did not elicit any positive reaction. Using this system, a panel of serum samples was screened for anti-Kingella antibodies in order to identify horses that had potentially been exposed to Kingella.

\section{Results}

\section{Serum Samples from Mares and their Respective Foals (now Weanlings or Yearlings) on Farm A were Tested for any Evidence of Antibodies by LED-IFAT}

Results are shown in Table 1 below. As the LED-IFAT test was negative for all 8 samples derived from Farm A, (denoting no evidence of exposure to Kingella bacteria in this herd), residents of Farm A (and their serum samples) served as negative controls.

\begin{tabular}{|c|c|c|l|}
\hline & Name of the foal & Date (serum sample) & Date (Serum sample) \\
\hline Farm -A & & & \\
\hline & Control Mare and foal & $15 / 5 / 13$ & \\
\hline & A1 M & $15 / 5 / 13$ & \\
\hline & A1 F & $15 / 5 / 13$ & \\
\hline & A2 M & $15 / 5 / 13$ & \\
\hline & A2 F & $15 / 5 / 13$ & \\
\hline & A3 M & $15 / 5 / 13$ & \\
\hline & A3 F & $15 / 5 / 13$ & \\
\hline
\end{tabular}

Rajasekariah GH, et al. Study of Seroprevalence and Seroconversion to A Novel Bacterial Pathogen in Thoroughbred Horses. Virol Immunol J 2019, 3(1): Copyright@ Rajasekariah GH, et al. 000203. 


\section{Virology \& Immunology Journal}

\begin{tabular}{|c|c|c|c|}
\hline & $\mathrm{A} 4 \mathrm{M}$ & $15 / 5 / 13$ & \\
\hline & A4 F & $15 / 5 / 13$ & \\
\hline \multicolumn{4}{|l|}{ Farm -B } \\
\hline & B-1 & $25 / 9 / 12$ & $9 / 11 / 2012$ \\
\hline & $\mathrm{B}-2$ & $9 / 10 / 2012$ & $9 / 11 / 2012$ \\
\hline & B-3 & $28 / 08 / 12$ & $9 / 10 / 2012$ \\
\hline & B-4 & $28 / 08 / 12$ & $9 / 11 / 2012$ \\
\hline & B-5 & $27 / 09 / 12$ & $9 / 10 / 2012$ \\
\hline & B-6 & $28 / 08 / 12$ & $9 / 10 / 2012$ \\
\hline & B-7 & $28 / 08 / 12$ & $9 / 11 / 2012$ \\
\hline & B-8 & $28 / 08 / 12$ & $11 / 10 / 2012$ \\
\hline & B-9 & $28 / 08 / 12$ & $15 / 10 / 12$ \\
\hline & $\mathrm{B}-10$ & $24 / 09 / 12$ & $9 / 10 / 2012$ \\
\hline \multicolumn{4}{|l|}{ Farm -C } \\
\hline & C-1 & $14 / 06 / 13$ & $11 / 7 / 2013$ \\
\hline & $\mathrm{C}-2$ & $14 / 06 / 13$ & $11 / 7 / 2013$ \\
\hline & C-3 & $14 / 06 / 13$ & $11 / 7 / 2013$ \\
\hline & \multirow{2}{*}{ C-4 } & \multirow{2}{*}{$19 / 02 / 13$} & $28 / 02 / 13$ \\
\hline & & & $9 / 5 / 2013$ \\
\hline & $C-5$ & $12 / 2 / 2013$ & $9 / 7 / 2013$ \\
\hline & C-6 & $15 / 02 / 13$ & $24 / 04 / 13$ \\
\hline & $\mathrm{C}-7$ & $17 / 02 / 13$ & $24 / 04 / 13$ \\
\hline & $\mathrm{C}-8$ & $14 / 06 / 13$ & $11 / 7 / 2013$ \\
\hline & C-9 & $26 / 02 / 13$ & $9 / 5 / 2013$ \\
\hline
\end{tabular}

Table 1: Chronology of serum samples tested from three Farms for antibodies against Kingella bacterium in LED-IFAT methodology (Farm A,B,C).

\section{Positive Control for LED-IFAT}

The serum sample from horse B-20 was consistently positive for anti-Kingella antibodies and formed indexcase. This serum was used as positive control for the development of LED-IFAT. Different dilutions of the serum sample were titrated and tested for optimal fluorescence intensity. It was determined that $1 / 400$ dilution was optimal and therefore unknown sera were tested at this $(1 / 400)$ dilution (Figures 2 and 3) and with no background (negative control, Fig 4).

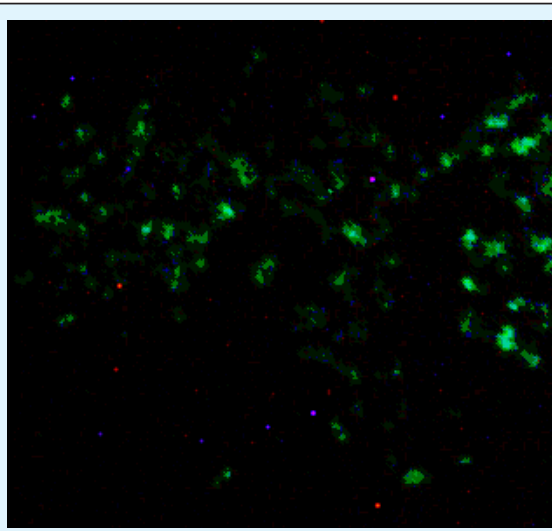

Fig 2: Positive control: B-20 serum tested at $1 / 400$ dilution from Farm -B. 


\section{Virology \& Immunology Journal}

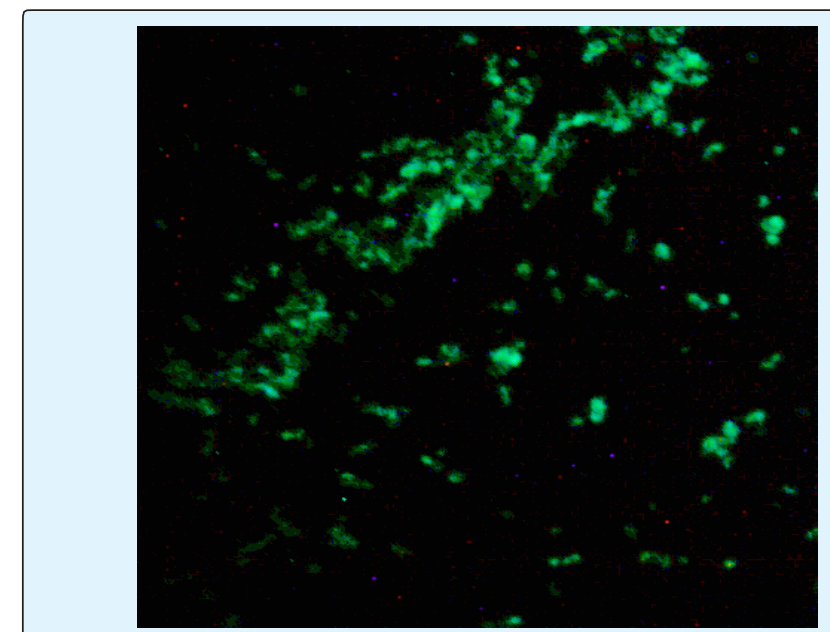

Fig 3: Index case B-20 foal serum at 1/400 dilution showed positive reaction against $K$. equi (Horse) substratum slide.
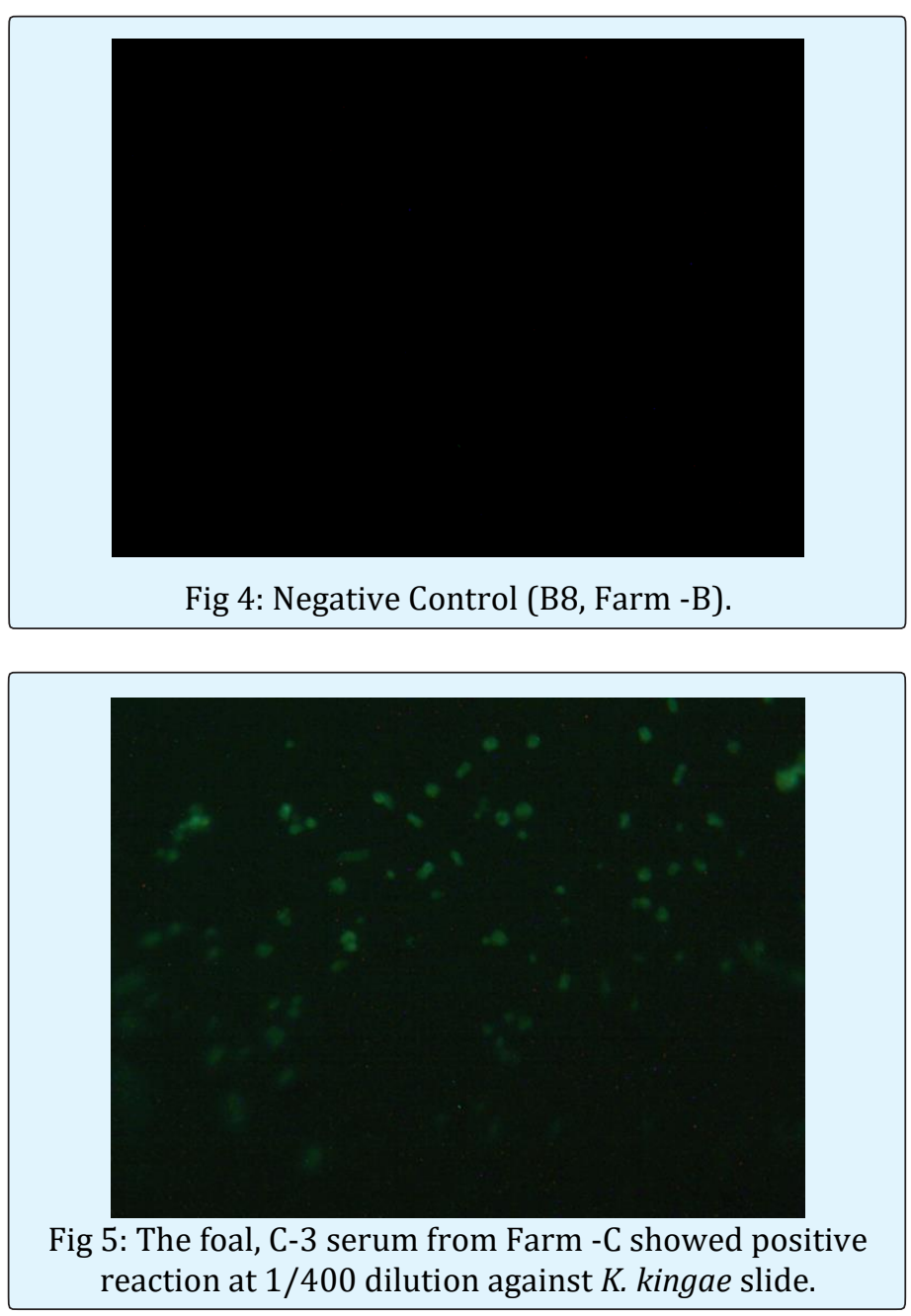


\section{Virology \& Immunology Journal}

\section{Serum Samples from Farm-B Tested for Presence of Antibodies against Kingella bacteria by LED-IFAT}

A total of $n=21$ samples were tested for presence of antibodies against Kingella organisms. Serum samples were tested at $1 / 400$ to $1 / 3200$ dilutions. Results are plotted in Fig 6. Five foals B-3, B-4, B-6, B-8 and B-11 demonstrated antibody response when tested their sera; of which 3 were consistently positive on two occasions. Examples of the IFAT slides are shown in Fig 7, 8 and 9. Presence of antibodies in the serum of foals against the bacterium suggests possible exposure to Kingella infection. One foal from B-7 had a bacterium, closely related to Kingella (Moraxella), isolated but lacked any specific antibodies to Kingella, suggesting that this antiKingella LED-IFAT on serum may be specific for Kingella infection.
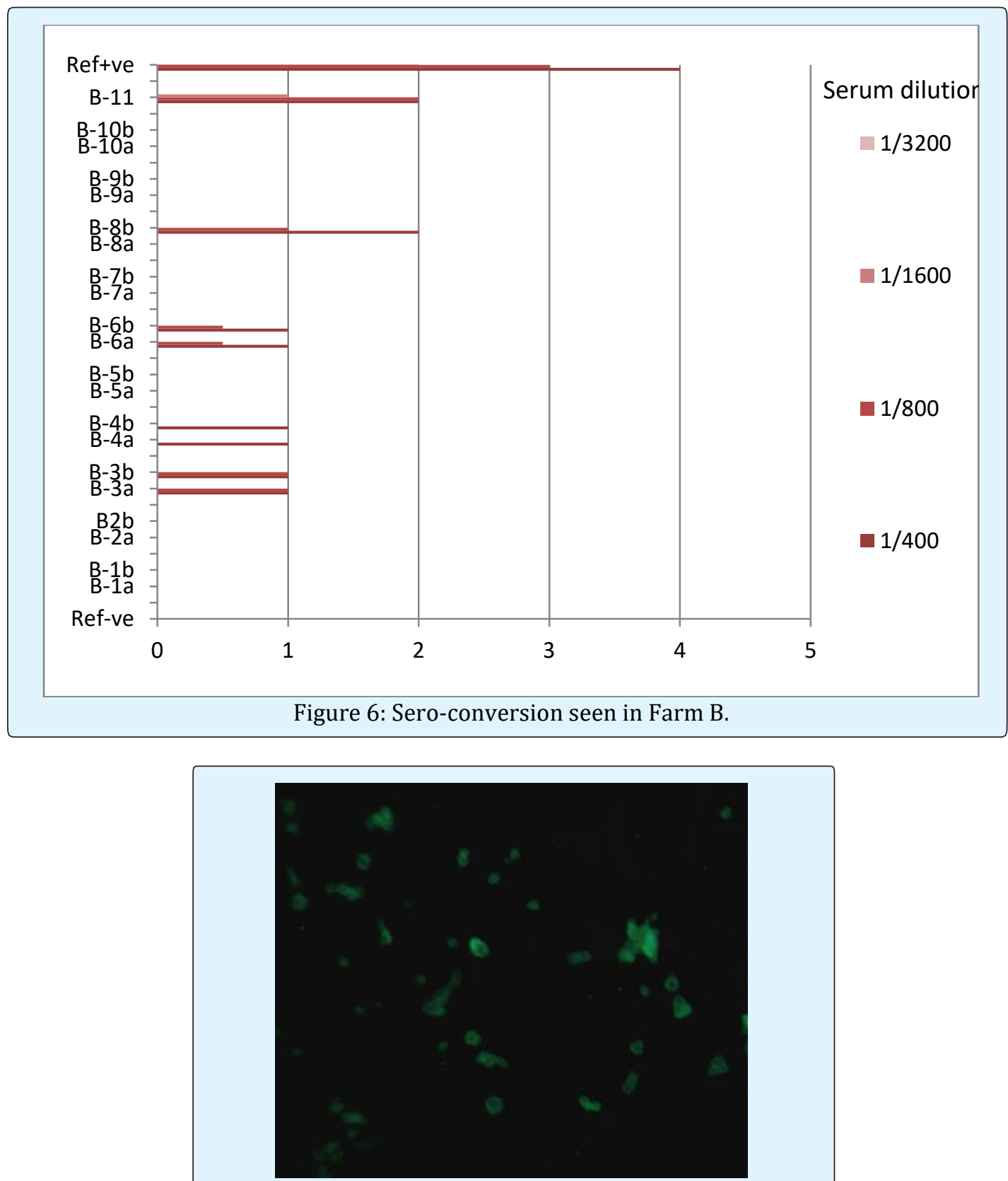

Figure 7: The foal, B-3 from Farm- B became seropositive at $1 / 400$ serum dilution against $K$.kingae (Human) slides. 


\section{Virology \& Immunology Journal}

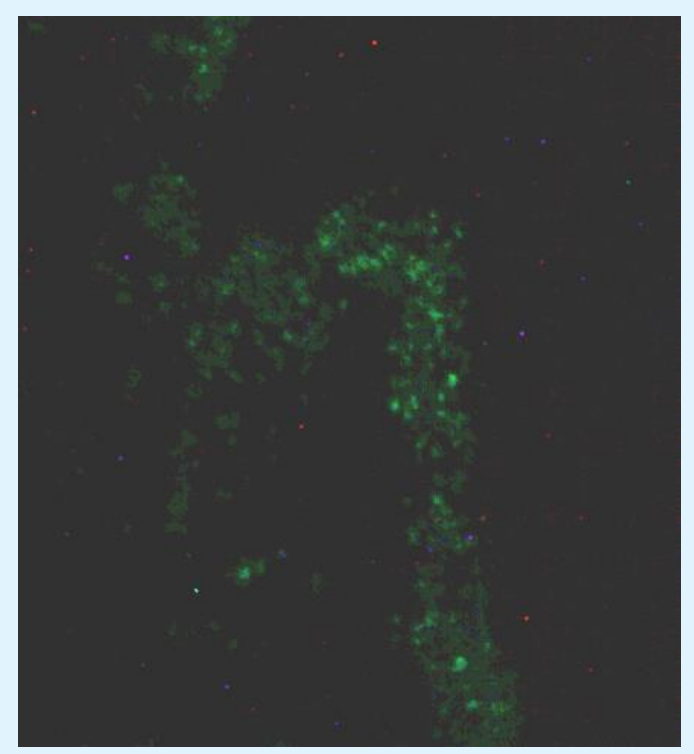

Figure 8: The foal, B-8 from Farm- B became seropositive at $1 / 400$ serum dilution against $\mathrm{K}$. kingae (Human) slides.

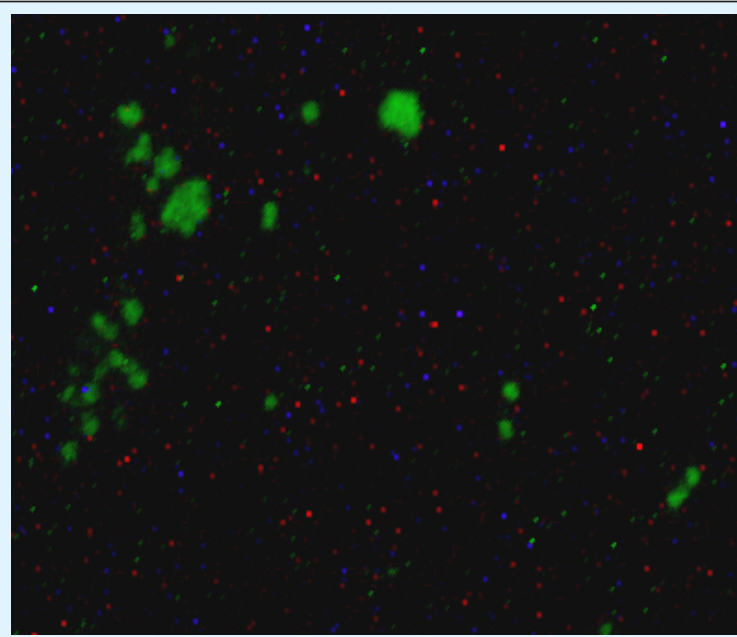

Fig 9: The B-3 foal serum at 1/400 dilution against K. equi (Horse) substratum showed positive reaction.

\section{Serum Samples from Farm-C}

A total of $n=19$ samples were tested for presence of antibodies against Kingella organisms. Serum samples were tested at $1 / 400$ to $1 / 3200$ dilutions. One horse (C-3) was found to have sero-converted (Figure 5).
For Farm A and Farm B, therefore, a total of $n=20$ horses were tested for the presence of antibodies against Kingella. Results are plotted in Figure 6 and 10 below. The presence of antibodies in the serum of horses against K. kingae and K. equi, as detected by LED-IFAT, suggests possible exposure to Kingella infection. 


\section{Virology \& Immunology Journal}

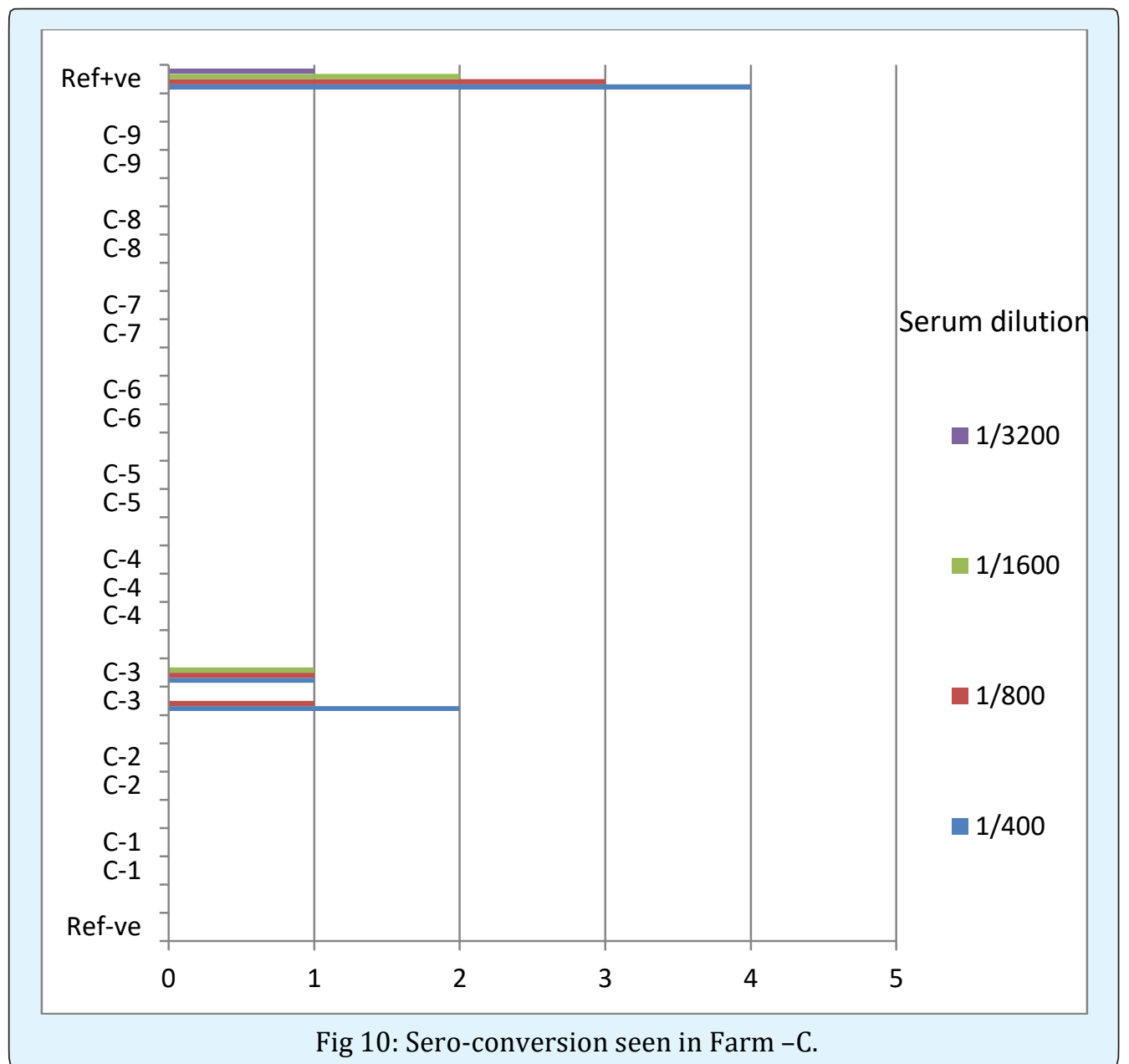

Serum samples tested against human isolate $K$. kingae and horse isolate $K$. equi and Test of Concordance

Serum from the index case was used as positive control with strong immunofluorescence (Figure 2, Figure 3). This shows that antibody response is detectable using any either K. kingae or K. equi and the IF reaction is identical. A total of 32 serum samples were tested in parallel by LED-IFAT using spotted multi-well slides prepared from bacteria K. kingae (human isolate) and $K$. equi (horse isolate) and analysed by Concordance test. There were 20 positives using K. kingae (human isolate) and 21 using $K$. equi (horse isolate). Very good concordance existed between results with the serology using $K$. kingae (human) and K. equi (horse). Test results are shown in Table 2. Because of this high concordance, using either $K$. kingae or the novel equine isolate (K. equi) as the basis for the LED-IFAT test seems acceptable.

\begin{tabular}{|c|c|c|c|c|c|}
\hline & $\begin{array}{c}\text { Kingella kingae } \\
\text { (human)POSITIVE }\end{array}$ & $\begin{array}{c}\text { Kingella kingae } \\
\text { (human)NEGATIVE }\end{array}$ & Total & $\begin{array}{c}\text { Test of } \\
\text { Concordance }\end{array}$ & Percent \\
\hline $\begin{array}{c}\text { Kingella equi } \\
\text { (Horse) POSITIVE }\end{array}$ & 19 & 2 & 21 & $\begin{array}{c}\text { Negative } \\
\text { Concordance }\end{array}$ & 91 \\
\hline $\begin{array}{c}\text { Kingella equi } \\
\text { (Horse) NEGATIVE }\end{array}$ & 1 & 10 & 11 & $\begin{array}{c}\text { Positive } \\
\text { Concordance }\end{array}$ & 91 \\
\hline Total & 20 & 12 & 32 & Discordance & 7 \\
\hline
\end{tabular}

Table 2: Correlation of positivity between Kingella kingae and K. equi. 


\section{Virology \& Immunology Journal}

\section{Discussion}

Invasive infection with $K$. kingae is thought to begin with the bacterium colonizing the pharynx, crossing the mucosa, thence entering the circulation and reaching deeper tissues, such as bones and joints. Poor oral hygiene, pharyngitis, mucosal ulceration and recent virus infection, including herpes group viruses, may be predisposing factors for invasive infection [8]. In humans, infection has been shown to have higher prevalence in the autumn and winter months. As an oro-pharyngeal colonizer, $K$. kingae is transmitted via respiratory secretions, saliva, direct contact and, potentially, oral contact with contaminated objects (e.g. fomite spread). Recent studies suggest $K$. kingae strains demonstrate varying degrees of pathogenicity [8]. These points may also be relevant to equine infection with the novel bacterium, referred to as $K$. equi for now. with respect to acquisition, transmission and invasive disease such as OAI.

Development of a reliable LED-IFAT depends upon careful selection of the optimal serum dilution to be used for the given test. Unless this is investigated thoroughly, non-specific binding of antibodies may be difficult to overcome. LED-IFAT as "the test of choice" for detection of antibodies has been applied to the investigation of several types of infection in horses: (a) equine protozoal myeloencephalitis [9], (b) Potomac horse fever due to Ehrlichia [10, 11], and (c) equine piroplasmosis [12, 13, 14]. These reports adjudge IFAT to be both reliable and the test of choice for detection of seroconversion. LEDIFAT is being extensively used for investigating the Sarcocystis neurona [15] which is showing $83 \%$ sensitivity and $97 \%$ specificity whereas Duarte et al. [16] compared IFAT and western blots for diagnosis of equine protozoal myeloencephalitis and recorded very higher (91 to $100 \%)$. In Korea seroprevalence of foals is investigated in Jeju Island, South Korea against Neospora, Toxoplasma and Sarcocystis and recorded very low seroconversion (2\% and $2.6 \%$ seroconversion) by IFAT for Neospora and Toxoplasma respectively whereas horses do not show response against Sarcocystis [17].

The main intention of this pilot serology survey was to examine whether yearlings have antibodies to Kingella and, thereafter, to detect seroconversion, as the latter can assist with further investigation of events surrounding such seroconversion. Apart from aiding with such investigation, it can also reinforce the basic principle of clinical and subclinical illness. Some horses may seroconvert with no evidence of infection while others may seroconvert and show clinical illness e.g. OAI. It is hypothesized that the immune system of the horses must have responded to bacterial invasion (by Kingella) and thereby generated specific antibodies. Those yearlings, which were found to be positive for antibodies, have been designated as "seropositives". We found 5 seropositives out of 10 foals tested from Farm B whereas there was only 1 seropositive out of 9 foals tested from Farm C. This preliminary investigation supports the hypothesis that invasive Kingella infection occurs in yearlings and that some of the yearlings affected by invasive infection develop OAI. When a more virulent strain is introduced into the herd (or develops by mutation of a low virulence strain that is already in the herd), more cases of OAI will likely be detected. Further testing on a larger number of sera was advised to confirm this finding. The hypothesis is therefore that a positive LED-IFAT result likely indicates exposure to Kingella, and infection monitor is suggested (Table 3).

A larger serosurvey, supported by molecular assays, will enable determination of prevalence of horses in the herd with antibodies (seroprevalence) as well as the percentage of horses that are seroconverters. Additionally, closer assessment of the time at which seroconversion has occurred should enable clarification of the epidemiology of the infection. Specifically, horse movements and exposures around the time of seroconversion could be pinpointed with a view to implementing control measures. For example, one horse (B-8) seroconverted between 28 August 2012 and 15 October 2012. Exposure to $K$. equi occurred more likely sometime between 18 August 2012 and early October 2012. By checking movements and exposures of this horse one may gain insight into why exposure occurred and how it could be prevented. Likewise, for any other yearlings who have an initial negative Kingella antibody test result but then become Kingella antibody positive, it may be possible to glean valuable information on exposure. This could lead to implementation of measures that may facilitate prevention of invasive disease including OAI.

In conclusion, this report is the first recorded serosurvey for detection of equine antibodies to a novel bacterial pathogen, resembling $\mathrm{K}$. kingae. The method used (LED-IF) is robust and easy to perform and could potentially be used to screen equine populations on a wider basis, for individual testing (infection status exposed, unexposed, seroconverted) as well as herd testing to pre-emptively identify introduction of the novel 
bacterial pathogen into the herd and identify the need for further epidemiological investigations.

\begin{tabular}{|c|c|}
\hline \multicolumn{2}{|c|}{ Kingella Infection Monitor } \\
\hline Current & Future \\
\hline 1. Microscope based LED-IF assay & $\begin{array}{c}\text { 1. Investigation } \\
\text { for epidemiology }\end{array}$ \\
\hline $\begin{array}{c}\text { 2. Both human isolate } \text { K. kingae } \\
\text { and horse isolate K. equi are used } \\
\text { for performing LED-IF assay }\end{array}$ & $\begin{array}{c}\text { 2. Development of } \\
\text { molecular } \\
\text { techniques if } \\
\text { required }\end{array}$ \\
\hline 3. Disease monitoring in stud- \\
farms. & $\begin{array}{c}\text { 3. Assay for } \\
\text { monitoring the } \\
\text { movement of } \\
\text { horses }\end{array}$ \\
\hline 4. Mares and yearlings can be \\
tested periodically. & $\begin{array}{c}\text { 4. Preventive } \\
\text { measures for } \\
\text { yearlings }\end{array}$ \\
\hline & $\begin{array}{c}\text { 5. Vaccines and } \\
\text { other preventive } \\
\text { measures }\end{array}$ \\
\hline
\end{tabular}

Table 3: Kingella Infection Monitor.

\section{References}

1. Henriksen SD, Bøvre K (1976) Transfer of Moraxella kingae Henriksen and Bøvre to the genus Kingella gen. nov. in the family Neisseriaceae. Int J Syst Bacteriol 26(4): 447-450.

2. Yagupsky P, Dagan R (1997) Kingella kingae: an emerging cause of invasive infections in young children. Clin Infect Dis 24(5): 860-866.

3. Lawson PA, Malnick H, Collins MD, Shah JJ, Chattaway MA, et al. (2005) Description of Kingella potus sp. nov., an organism isolated from a wound caused by an animal bite. Journal of Clinical Microbiology 43(7): 3526-3529.

4. Robinson NE, Sprayberry K (2008) Current Therapy in Equine Medicine. Elsevier Publishers.

5. Yagupsky P (2014) Outbreaks of Kingella kingae infections in Daycare Facilities. Emerging Infectious Diseases 20(5): 746-753.

6. Principi N, Esposito S (2015) Kingella kingae infections in children. BMC Infectious Diseases 15: 260.

\section{Virology \& Immunology Journal}

7. Ferroni A, Al Khoury H, Dana C, Quesne G, Berche P, et al. (2013) Prospective survey of acute osteoarticular infections in a French paediatric orthopedic surgery unit. Clinical Microbiology and Infection 19(9): 822-828.

8. Yagupsky P (2015) Kingella kingae: carriage, transmission, and disease. Clin Microbiol Rev 28(1): 54-79.

9. Duarte PC, Daft BM, Conrad PA, Packham AE, Gardner IA (2003) Comparison of a serum indirect fluorescent antibody test with two western blot tests for diagnosis of equine protozoal myeloencephalitis. J Vet Diagnostic Investigation 15(1): 8-13.

10. Nicholson WL, Comer JA, Sumner JW, Gingerich-Baker C, Coughlin RT, et al. (1997) An indirect immunofluoresecence assay using a cell culturederived antigen for detection of antibodies to the agent of human granulocytic ehrlichosis. J. Clin Microbiology 35(6): 1510-1516.

11. Mott J, et al. (1997) Potomac horse fever due to Ehrlichia. J Clin Microbial 22: 15-19.

12. De Waal DT (1992) Equine piroplasmosis: A review. British Vet J 148(1): 6-14.

13. OIE (2014) Terrestrial Manual Equine piroplasmosis Chapter 2.5.8. World assembly of Delegates of the OIE; pp: 10.

14. Kuttler KL, Goff WL, Gipson CA, Blackburn BO (1988) Serological response of Babesia equi -infected Horses as measured by complement-fixation and indirect fluorescent antibody tests. Vet Parasitol 26(3-4): 199205.

15. Pusterla N, Packam AE, Wilson WD, White A, Bellamy P, et al. (2013) Evaluation of the kinetics of antibodies Against Sarcocystis neurona in serum of seropositive healthy horses without neurological deficits treated with ponazuril past. Vet record 173(10).

16. Duarte PC, Daft BM, Conrad PA, Packham AE, Saville WJ, et al. (2004) Evaluation and comparison of an indirect fluorescent antibody test for detection of antibodies to Sarcocystis neurona, using serum and cerebrospinal fluid of naturally and experimentally infected and vaccinated horses. J Parasitol 90(2): 379386. 


\section{Virology \& Immunology Journal}

17. Gupta GD, Lakritz J, Kim JH, Kim DY, Kim JK, et al. (2002) Seroprevalence of Neospora, Toxoplasma gondi and Sarcocystis neurona antibodies in horses from Jeju island, South Korea. Veterinary Parasitology 106(3): 193-201 